\title{
Towards the Solution of Abysmal Performance of Fraction in Navrongo Presbyterian Primary School: Comparing the Sets of Objects and Paper Folding Designed Interventions
}

\author{
Christiana Subaar ${ }^{1}$, Juliana Awune Asechoma ${ }^{2}$, Vincent Ninmaal Asigri², Victor Alebna ${ }^{2}$, \\ Francis Xavier Adams ${ }^{2}$ \\ ${ }^{1}$ Department of Science, St. John Bosco's College of Education, Navrongo, Ghana \\ ${ }^{2}$ Department of Mathematics, St. John Bosco's College of Education, Navrongo, Ghana
}

Email address:

ysubaar@gmail.com (C. Subaar)

To cite this article:

Christiana Subaar, Juliana Awune Asechoma, Vincent Ninmaal Asigri, Victor Alebna, Francis Xavier Adams. Towards the Solution of Abysmal Performance of Fraction in Navrongo Presbyterian Primary School: Comparing the Sets of Objects and Paper Folding Designed Interventions. Science Journal of Applied Mathematics and Statistics. Vol. 6, No. 4, 2018, pp. 119-123. doi: 10.11648/j.sjams.20180604.12

Received: August 10, 2018; Accepted: August 29, 2018; Published: September 21, 2018

\begin{abstract}
This is an interventional study sought to find the difference in the performance of pupils who were taught using sets of objects (sets model) and paper folding activities, to solve word problems involving addition and subtraction of proper fractions. A total of thirty pupils, of Navrongo Presbyterian Primary School Basic Five A, were used in the study. A wellstructured lesson, with teaching and learning materials, was used. A pretest and posttest assessments were deployed to ascertain the effect of the interventional teaching strategies. Prior, to the intervention of the study, $73.3 \%$ of the pupils (total of 30 ) scored below the average mark ranging from 5-7. These represented the experimental group of the study. $26.7 \%$ of the pupils (control group) scored the average mark. However, after the intervention, both strategies (sets of objects and paper folding activities) showed remarkable performance. Although both strategies showed remarkable performance in pupils, $59 \%$ of the experimental group (total of 22 pupils) scored above the average mark in the paper folding as compared to $50 \%$ of the experimental group who scored above the average mark in the usage of sets model. While $87.5 \%$ of the control group scored above the average marks ranging from 8-10 during the paper folding activities, $62.5 \%$ of the control group scored above the average marks from 8-10 during the use of sets model. The posttest results of both the control and experimental groups taught using paper folding performed far better compared to sets model. The study has shown that pupils' level of performance had improved drastically with the help of paper folding method. In conclusion, paper folding activities help pupils to appreciate word problems involving addition and subtraction of proper fractions.
\end{abstract}

Keywords: Experimental Group, Folding, Fraction, Paper, Proper

\section{Introduction}

Fractions have been known from ancient civilizations until current times, but they still pose major problems when learning mathematics. Babylonian civilization and Egyptians of 4000 years ago already worked with fractions. The processing of fractions is part of everyday life and its use in situations such as reading of analogue clocks, in particular, the key times of quarter past, a half past and a quarter to, all hold a bit less importance with the advert and uptake of digital timepieces $[1,2]$. Moreover, fractions play a key role in mathematics, since they are involved in probabilistic, proportional and algebraic reasoning. Fractions have been used for centuries and are manipulated in a great variety of everyday life situations and in mathematics, and yet they are hard for pupils to grasp and master [3, 4].

Fractions are well-known to constitute a stumbling block for primary school children [5]. Understanding difficulties in learning fractions seem absolutely crucial as they can lead to mathematics anxiety, and affect opportunities for further engagement in mathematics and science $[6,7]$. The abysmal performance in mathematics among basic school pupils is evident in the results of the trends in Basic Education Certificate Examination (BECE) conducted annually by the 
West African Examination Council (WAEC, 2008, 2009, 2010, 2011) [8].

Poor performance in mathematics at the basic level of education in Ghana has attracted a lot of attention of the government, mathematics educators, educational researchers, instructional designers, parents and employers and calls for immediate solutions. Various hypotheses have been proposed in order to explain those difficulties [9, 10]. Despite fraction instruction beginning in elementary school, many people fail to gain a firm understanding of fractions and harbor misconceptions through high school and college [11, 12]. This is a serious problem, because understanding of fractions is a foundational mathematical skill and can chiefly be considered in three broad categories: rational fractions, fractions as operators and equivalent fractions and can be represented as: part of a whole, a place on the number line, an answer to a division calculation and a way of comparing two sets $[13,14]$.

Using multiple models to teach fractions is important because it assists pupils to generalize their understanding of fractions. For most children, especially pupils with learning difficulties, paper folding is easier teaching strategy to grasp the concept of fractions compared to the sets model shown in Figure 1 for teaching and understanding of fractions [15].

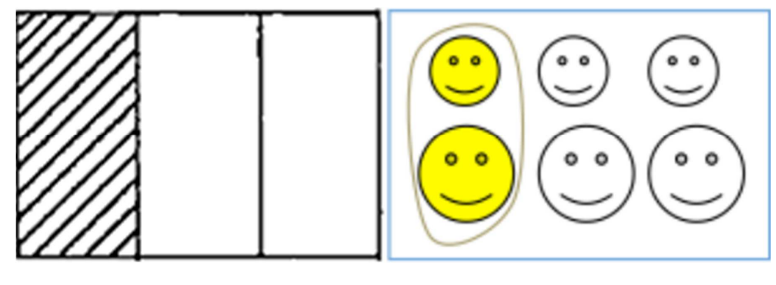

Paper Folding Sets Model

Figure 1. Teaching the concept of Fractions [15].

The differences in pupils' mathematics performance may be a function of the amount and kind of exposure to mathematical instruction rather than in real differences inabilities. The quality of the teaching is paramount in learning of mathematics topic of fractions $[16,17]$.

This study, therefore, sought to find the difference in the performance of pupils taught using sets model and paper folding activities to assist Navrongo Presbyterian Primary Five A located at Kassena-Nankana East District of Upper East Region, to solve word problems involving addition and subtraction of proper fractions. This study attempts to improve pupils of Navrongo Presbyterian Five Primary school mathematics knowledge in general, and their fraction understanding in particular.

\section{Materials and Methods}

The interventional study was conducted for a period of three weeks. The first week was used for a pre-intervention test (pretest), the second week was used for the intervention activities and the last week was used for a post-intervention test (posttest). The target group was sampled into control and experimental groups. The remedial action of the study was administered to both experimental and control groups, with much attention been paid on the former group and the latter group was used to find out the effectiveness of the intervention by comparing the performance of the two groups after the interventions. All the primary five A pupils (total of 30) of Navrongo Presbyterian primary school, Kasena-Nakana East District of the Upper East Region, Ghana, were recruited for the study. They consisted of seventeen (17) girls and thirteen (13) boys; with a mean age of 9.0 \pm 2 years.

\subsection{Pretest}

A teacher-made pretest was conducted to diagnose the exact extent of the problem identified with the pupils. The questions required pupils to add and subtract proper fractions. Each pupil was given a printed question paper and an answer sheet. The pupils used thirty-five (35) minutes to write the test. All the pupils took the pretest.

\subsection{Intervention}

Paper folding and sets model such as bottle top, balls and oranges were used during the intervention in delivering the lessons. Lessons were delivered to both control and experimental groups at the same schedules. Sets model and paper folding activities were used to assist pupils to solve addition and subtraction of proper fraction involving word problem. The impact of both activities was compared.

\subsection{Posttest}

The researchers conducted a posttest after the intervention to ascertain how effective and successful the intervention activities had been. The same questions used in the pretest were used for the posttest. The instructions and conditions of the pretest were used for the posttest. All the pupils took the posttest.

\section{Results}

Table 1 presents pretest scores distribution on proper fraction. None of the pupils scored above 7 marks. Table 2 is the summary pretest performance of Table 1. Base on Table 2, twenty (22) pupils representing $73.3 \%$ of thirty pupils scored below the average mark ranging from 5-7 who were considered as the experimental group. Eight (8) pupils representing 26.7\% scored the average mark ranging from 5-7 while no pupil scored above average mark.

Table 1. Pretest Score Distribution on Proper Fraction.

\begin{tabular}{lll}
\hline Marks & Pupils & Percentages (\%) \\
\hline 1 & 9 & 30 \\
2 & 6 & 20 \\
3 & 3 & 10 \\
4 & 4 & 13.3 \\
5 & 3 & 10 \\
6 & 3 & 10 \\
7 & 2 & 6.7 \\
8 & 0 & 0 \\
9 & 0 & 0 \\
10 & 0 & 0 \\
Total & 30 & 100 \\
\hline
\end{tabular}


Table 2. Summary of Pupils Pretest Performances.

\begin{tabular}{llll}
\hline Marks & Pupils & Percentages (\%) & Remarks \\
\hline $1-4$ & 22 & 73.3 & Below Average \\
$5-7$ & 8 & 26.7 & Average \\
$8-10$ & 0 & 0.0 & Above Average \\
Total & 30 & 100 & \\
\hline
\end{tabular}

Table 3 indicates that $13(59 \%)$ of the experimental group (total of 22) scored the above average mark from 5-7 and 7
(31.8\%) scored the average mark from 5-7 when taught using paper folding method. $11(50 \%)$ of the experimental group scored the above average mark from 5-7, and 6 (27.3\%) scored the average from 5-7 when taught using sets model. Whilst only $2(9 \%)$ of the experimental group scored below the average mark of 5-7 during paper folding activities, 5 (22.7\%) pupils scored below the average mark from 5-7 during set model activities.

Table 3. Comparing the Experimental Group Performance of Posttest Results of Paper Folding and Sets Model.

\begin{tabular}{|c|c|c|c|c|c|}
\hline Marks & Pupils & Paper Folding Percentages & Pupils & Sets Model Percentages & Remarks \\
\hline $1-4$ & 2 & 9 & 5 & 22.7 & Below Average \\
\hline $5-7$ & 7 & 31.8 & 6 & 27.3 & Average \\
\hline $8-10$ & 13 & 59 & 11 & 50 & Above Average \\
\hline
\end{tabular}

Table 4 presents the comparison of control group performance of posttest results of paper folding and sets model. No pupil scored below the average mark from 1-4 on both the paper folding and sets model.

Table 4. Comparing the Control Group Performance of Post-Test Results of Paper Folding and Sets Model.

\begin{tabular}{|c|c|c|c|c|c|}
\hline Marks & Pupils & Paper Folding Percentages (\%) & Pupils & Sets Model Percentages (\%) & Remarks \\
\hline $1-4$ & 0 & 0 & 0 & 0 & Below Average \\
\hline $5-7$ & 1 & 12.5 & 3 & 37.5 & Average \\
\hline $8-10$ & 7 & 87.5 & 5 & 62.5 & Above Average \\
\hline Total & 8 & 100 & 8 & 100 & \\
\hline
\end{tabular}

Figure 2. depicts pupils' performance during paper folding activities as compared with the activities involving sets of objects.

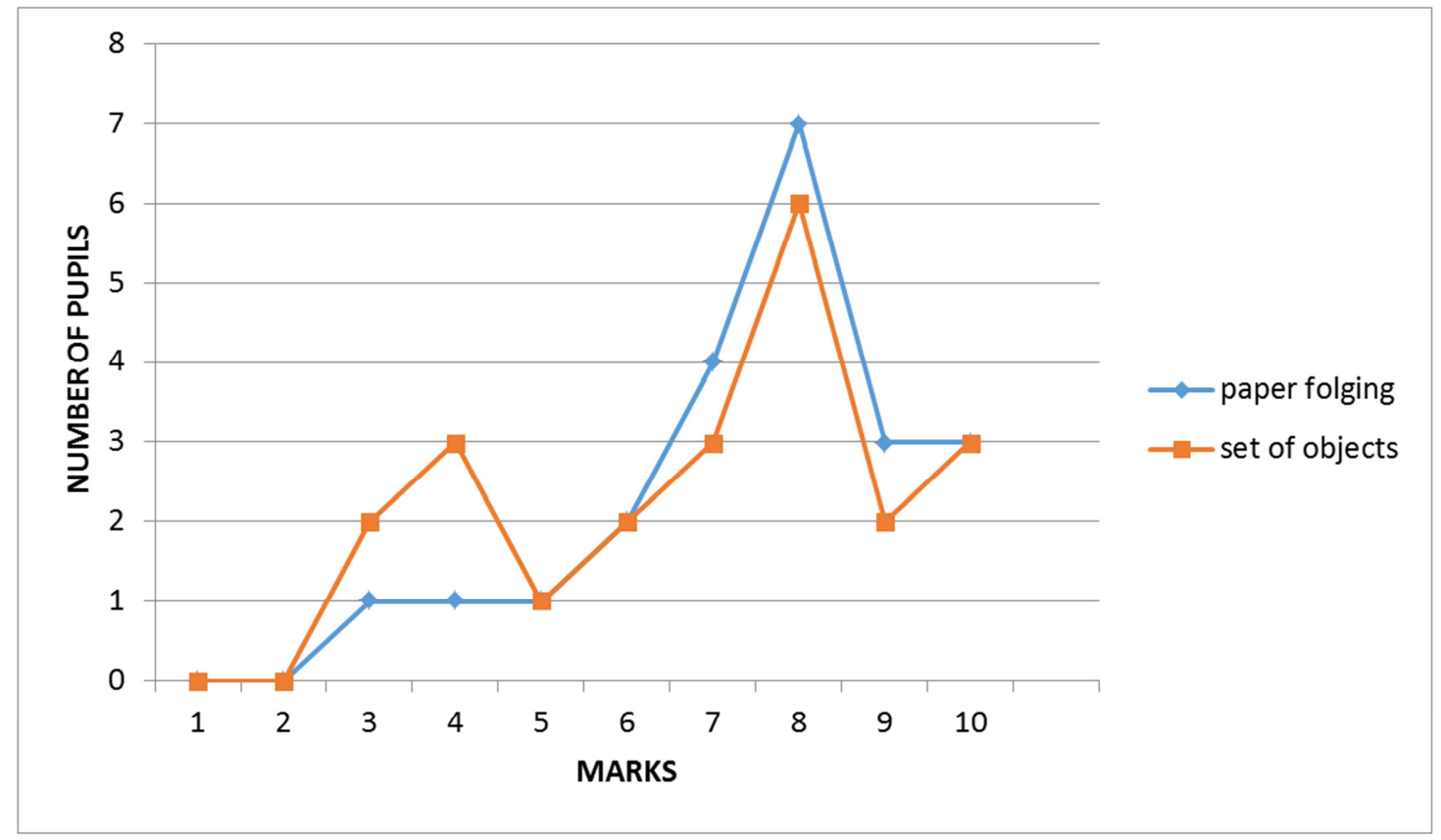

Figure 2. Experimental Analysis of Pupil's Performance using Paper Folding and Sets Model.

\section{Discussion}

The pretest results (Table 1 and 2) showed that pupils had little knowledge and understanding of solving word problems involving addition and subtraction of proper fractions. Table 2 indicates that twenty (22) pupils representing 73.3\% of thirty pupils scored below the average mark ranging from 57. The pretest revealed that pupils apply procedures that they do not understand to solve word problems involving addition and subtraction of proper fractions.

After the intervention, the experimental group posttest performance results shown in Table 3 indicated that $59 \%$ of the experimental group scored the above average mark from $5-7,31.8 \%$ scored the average mark from 5-7 and 9\% scored below the average mark ranging from 5-7 using the paper folding method. On the other hand, the sets model used revealed that $50 \%$ of the experimental group scored above the average mark ranging from $8-10,27.3 \%$ scored the 
average mark from 5-7, and $22.7 \%$ scored below the average mark from 1-4. Also from the control group results shown in Table 4, no pupil scored below the average mark from 1-4 on both paper folding and sets model. The Table 4 indicated that whilst $87.5 \%$ scored above the average mark of $8-10$ on the paper folding activities, only $12.5 \%$ of the control group scored the average mark of 5-7. Also, $37.5 \%$ and $62.5 \%$ of the control group scored the average mark from 5-7 and above average mark from 8-10 respectively when sets of objects were used. With these performances of the control group which were used to assess the effectiveness of the strategies used, the paper folding activities can be considered the best strategies for teaching addition and subtraction of word problems involving proper fractions.

Figure 2 depicts the experimental results of paper folding and sets model used to teach word problems involving proper fractions. After the researchers carried out the intervention process involving series of activities using paper folding and sets of objects, it can be clearly seen in Figure 2 that pupils perform well during the paper folding activities as compared with the activities involving sets of objects. The least mark scored during the paper folding was 3 and the highest marks 10 while the least mark scored during sets of objects was zero and the highest mark was 10 . Even though both activities recorded 10 marks as the highest mark of 3 pupils, $59 \%$ of the pupils scored above the average mark in paper folding as compared to $50 \%$ of pupils who scored above the average mark in the usage of sets of objects as shown in Table 3 of the experimental group. This study, therefore, agrees with [5] that paper folding is easier teaching strategy to grasp the concept of fractions compared to the sets model. From this study, $87.5 \%$ of the pupils scored above the average mark (5-7) in the paper folding as compared to $62.5 \%$ of pupils who scored above the average mark in the usage of sets model (Table 4). The study confirms [8] that the quality of teaching is paramount of learning of mathematics topic of fractions as shown in Table 4 of the control group which measures the effectiveness of the materials, methods, and strategies used for the intervention.

\section{Conclusion}

Since fractions play a key role in mathematics and mathematics creates a study and employment opportunities for individuals, it is fundamental that all students should have equitable to those opportunities. Primary school children struggle to solve word problems involving addition and subtraction of proper fractions. This might be linked to the pedagogy deployed by teachers. Pupils seemed to master the concept of fractions when taught using paper folding and posed colossal problems when taught using sets of objects (sets model). After the researchers carried out the intervention process, the posttest conducted showed that pupils' of Navrongo Presbyterian Primary school, Kasena-Nakana East, Upper East Region, Ghana, level of performance had improved drastically using the paper folding method. This study has therefore presented that the paper folding activity is a teaching strategy that makes the learning of fractions more enjoyable for pupils. It can, therefore, be concluded that paper folding teaching strategy helps pupils to apply procedures that they understand to solve word problems involving addition and subtraction of proper fractions.

\section{References}

[1] Gabriel, F. C., Coché, F., Szucs, D., Carette, V., Rey, B., \& Content, A. (2013). A componential view of children's difficulties in learning fractions. Frontiers in psychology, 4, 715 .

[2] Hurrell, D. (2013). Effectiveness of teacher professional learning: Enhancing the teaching of fractions in primary schools.

[3] Anthony, G., \& Ding, L. (2011). Teaching and learning fractions: Lessons from alternative example spaces. Curriculum Matters, 7, 159.

[4] Anthony, G., \& Walshaw, M. (2003). Pizza for dinner:"How much" or "how many". In Mathematics Education Research Group Association annual conference, Geelong.

[5] Baroody, A., Baroody, A. J., \& Coslick, R. T. (1998). Fostering children's mathematical power: An investigative approach to K-8 mathematics instruction. Routledge.

[6] Lave, J. (1988). Cognition in practice: Mind, mathematics and culture in everyday life. Cambridge University Press.

[7] Schoenfeld, A. H. (1992). Learning to think mathematically: Problem solving, metacognition, and sense making in mathematics. Handbook of research on mathematics teaching and learning, 334370.

[8] Tay, M. K., \& Wonkyi, T. M. (2018). Effect of using Geogebra on senior high school students' performance in circle theorems. African Journal of Educational Studies in Mathematics and Sciences, 14, 1-18.

[9] Kadingdi, S. (2006). Policy initiatives for change and innovation in basic education programmes in Ghana. Educate , 4(2), 3-18.

[10] Sarfo, F. K., Eshum, G., Elen, J., \& Adentwi, K. I. (2014). Towards the solution of abysmal performance in mathematics in junior high schools: Comparing the pedagogical potential of two designed interventions.

[11] Baroody, A. J., \& Hume, J. (1991). Meaningful mathematics instruction: The case of fractions. Remedial and Special Education, 12(3), 54-68.

[12] Fazio, L. K., Kennedy, C. A., \& Siegler, R. S. (2016). Improving children's knowledge of fraction magnitudes. PloS one, 11(10).

[13] Lamon, S. J. (2012).Teaching fractions and ratios for understanding: Essential content Knowledge and instructional strategies for teachers. Routledge.

[14] Lamon, S. J. (2013). MORE! Teaching Fractions and Ratios for Understanding: In-Depth. Discussion and Reasoning Activities. Routledge.

[15] Bezuk, N., \& Cramer, K. (1989). Teaching about fractions: What, when, and how. National council of teachers of mathematics, 156-167. 
123 Christiana Subaar et al:: Towards the Solution of Abysmal Performance of Fraction in Navrongo Presbyterian Primary School: Comparing the Sets of Objects and Paper Folding Designed Interventions

[16] Fuchs, L. S., Schumacher, R. F., Long, J., Namkung, J., Hamlett, C. L., Cirino, P. T. \& Changas, P. (2013). Improving at-risk learners' understanding of fractions. Journal of Educational Psychology, 105(3), 683.
[17] Chikwere, P., \& Ayama, K. Teaching of Geometric Construction in Junior High School: An Intervention. Journal of Elementary Education, 26(1), 139-146. 